OPEN ACCESS

Edited by:

Javier Blesa,

Centro Integral en Neurociencias A.C. HM CINAC, Spain

Reviewed by:

John W. Cave,

Weill Cornell Medical College, Cornell

University, United States

Carlos Crespo,

Universitat de València, Spain

María García-Amado

Universidad Autonoma de Madrid,

Spain

*Correspondence: Alino Martinez-Marcos alino.martinez@uclm.es

Received: 01 September 2017 Accepted: 21 November 2017

Published: 05 December 2017

Citation:

Ubeda-Bañon I, Flores-Cuadrado A

Saiz-Sanchez D and

Martinez-Marcos A (2017) Differential

Effects of Parkinson's Disease on

Interneuron Subtypes within the

Human Anterior Olfactory Nucleus.

Front. Neuroanat. 11:113.

doi: 10.3389/fnana.2017.00113

\section{Differential Effects of Parkinson's Disease on Interneuron Subtypes within the Human Anterior Olfactory Nucleus}

\section{Isabel Ubeda-Bañon, Alicia Flores-Cuadrado, Daniel Saiz-Sanchez and Alino Martinez-Marcos*}

Neuroplasticity and Neurodegeneration Laboratory, CRIB, Ciudad Real Medical School, University of Castilla-La Mancha, Ciudad Real, Spain

Synucleinopathies (including $\alpha$-synucleinopathies), which include Parkinson's disease $(P D)$, manifest themsevles early on (stage 1) in the olfactory system; preferentially in the anterior olfactory nucleus (AON). In particular, the non-motor, early manifestations of PD include hyposmia, which is the partial loss of the sense of smell. The neural basis of hyposmia in PD, however, is poorly understood; but the AON appears to be a key structure in the disease's progression. We analyzed whether $\alpha$-synuclein was involved in the differential interneuron vulnerability associated with PD in the retrobulbar, cortical anterior and cortical posterior divisions of the AON. First, we determined the expression of the calcium binding interneuron markers, calretinin, calbindin and parvalbumin, as well as non-calcium binding interneuron marker, somatostatin, in neuronal cell bodies alone (cells $/ \mathrm{mm}^{2}$ ) and in neuronal cell bodies and neurites (\% of area fraction) of post-mortem tissue from PD cases and age-matched controls ( $n=4$ for each) by immunofluorescent confocal microscopy. Results indicated that parvalbumin expression was upregulated in neuronal cell bodies throughout the anterior olfactory nucleus of PD cases compared with controls. Furthermore, there was increased calbindin, calretinin and parvalbumin expression in the cell bodies and neurites of neurons in the retrobulbar division and also increased parvalbumin expression in the neurites of neurons in the cortical division; calretinin expression was also increased in neuronal cell bodies and neurites in the cortical posterior division. Second, we analyzed the co-localization of the above markers with $\alpha$-synuclein, with results indicating that $\alpha$-synuclein co-localized with the calcium-binding proteins, but only partially with somatostatin. Taken together, these results indicate differential expression levels among different neural markers in the divisions of the $\mathrm{AON}$ in PD cases and point to several possibilities, among

\footnotetext{
Abbreviations: ACC, nucleus accumbens; AON, anterior olfactory nucleus; AONb, anterior olfactory nucleus, bulbar; $\mathrm{AONca}$, anterior olfactory nucleus, cortical anterior; $\mathrm{AONcp}$, anterior olfactory nucleus, cortical posterior; $\mathrm{AONi}$, anterior olfactory nucleus, intrapeduncular; $\mathrm{AONrb}$, anterior olfactory nucleus, retrobulbar; $\mathrm{C}$, control; $\mathrm{CB}$, calbindin; $\mathrm{CR}$, calretinin; DMSO, dimethyl sulfoxide; OB, olfactory bulb; OP, olfactory peduncle; ot, olfactory tract; PD, Parkinson's disease; PV, parvalbumin; REM, rapid eye movement; SG, straight gyrus; SST, somatostatin; $\alpha$-syn, $\alpha$-synuclein.
} 
them: possible neuroprotective mechanisms of calcium-binding proteins against $\alpha$ synuclein; and the differential involvement of somatostatin in $\alpha$-synuclein-positive cell bodies and neurites.

Keywords: calcium binding protein, non-motor symptoms, olfaction, somatostatin, $\alpha$-synucleinopathy

\section{INTRODUCTION}

The classical motor dysfunctions of Parkinson's disease (PD) are bradykinesia, rigidity, resting tremor and postural instability (Lees et al., 2009; Kalia and Lang, 2015; Poewe et al., 2017); while early non-motor manifestations include dysautonomia, rapid eye movement (REM) sleep disorder and hyposmia (Stiasny-Kolster et al., 2005; Berg et al., 2015; Postuma et al., 2015; Schapira et al., 2017). In parallel with the occurrence of non-motor and motor signs, neuropathological aggregates of $\alpha$-synuclein and ubiquitin, termed Lewy bodies and Lewy neurites (Spillantini et al., 1997; Goedert et al., 2013; Kalia and Kalia, 2015) appear in a predictable and cumulative six-stage sequence.

Two decades after the presence of $\alpha$-synuclein in Lewy bodies was demonstrated (Spillantini et al., 1997), the precise mechanism of $\alpha$-synucleinopathy in neurodegeneration remains unknown. Research in this area has revealed the following: (1) a prodromal period characterized by non-motor manifestations such as olfactory degeneration (hypnosmia), REM sleep disorder and constipation (Postuma and Berg, 2016; Sauerbier et al., 2016; Schapira et al., 2017); (2) aggregation of $\alpha$-synuclein has been used to establish a cumulative and predictable sequence of six neuropathological stages in PD (Del Tredici et al., 2002; Braak et al., 2003a,b; Del Tredici and Braak, 2016; Braak and Del Tredici, 2017). In stage I, the enteric nervous system-Meissner's and Auerbach's plexuses and the dorsal motor nucleus of the vagus nerve (Klingelhoefer and Reichmann, 2015)—and the olfactory system-the olfactory mucosa (Saito et al., 2016), the olfactory bulb (OB) and portions of the anterior olfactory nucleus (AON)-are involved. In stage II, $\alpha$-synucleinopathy progresses to the brainstem to reach the substantia nigra (stage III): the stage where motor symptoms appear and clinical diagnosis can be established (Del Tredici and Braak, 2016). Aggregation of $\alpha$-synuclein in the central and peripheral nervous system structures has been correlated with both non-motor and motor symptoms (Tolosa and PontSunyer, 2011; Salat et al., 2016), but a direct clinicopathologic relationship remains controversial (Burke et al., 2008). (3) In addition, the progression of $\alpha$-synucleinopathies is still a matter of current debate. Interestingly, there is accumulating evidence that $\alpha$-synucleinopathies associated with neurodegenerative diseases can spread via neuronal pathways in a prion-like misfolding and seeding aggregation manner (Jucker and Walker, 2013; Walker and Jucker, 2015). Furthermore, specific $\alpha$-synuclein conformations may be particularly toxic and relevant to non-motor manifestations without contributing to motor symptoms (Kalia and Kalia, 2015).

Although neural substrates of hyposmia in PD have not been identified (Doty, 2012a,b, 2017), initial entry sites of $\alpha$-synucleinopathies (Kalia and Kalia, 2015) include the enteric nervous system and the olfactory system (Braak et al., 2003a; Del Tredici and Braak, 2016; Braak and Del Tredici, 2017). Specifically, different divisions of the AON are preferentially involved (Hawkes and Shephard, 1993; Pearce et al., 1995; Braak et al., 2003a; Ubeda-Bañon et al., 2010, 2014; Attems et al., 2014; Del Tredici and Braak, 2016; Braak and Del Tredici, 2017).

To this end, we hypotheisize that the human $\mathrm{AON}$ is an early and preferential region of initial $\alpha$-synucleinopathy (Attems et al., 2014) in PD for several reasons: its peripheral location; and also its multiple short and long distance, centrifugal and centripetal, and bilateral neural connections (UbedaBañon et al., 2014). Analysis of the AON of postmortem PD patients can provide insight into the involvement and differential vulnerability of the various neuronal populations in this region. Previous reports have shown that in the olfactory system of $\mathrm{PD}$ patients, calcium-binding protein-expressing neurons are highly co-localized with $\alpha$-synuclein, which is rarely the case for tyrosine hydroxylase- or somatostatinpositive cells (Sengoku et al., 2008; Ubeda-Bañon et al., 2010). However, comparisons on differential neural vulnerability between PD and control cases in these structures have not been carried out.

In the present report, we compared the expression of calciumbinding proteins and somatostatin in the retrobulbar and cortical anterior and poster divisions of the AON (the anterior olfactory nucleus, retrobulbar (AONrb), anterior olfactory nucleus, cortical anterior (AONca) and anterior olfactory nucleus, cortical posterior (AONcp), respectively) in PD and control cases. This is the first report describing variable $\alpha$-synuclein susceptibility among specific neuronal populations in PD.

\section{MATERIALS AND METHODS}

\section{Human Brain Tissue}

Specimens from four neuropathologically diagnosed cases of PD (stages IV and V) and four age-matched controls were examined in this study (Table 1). Tissue blocks were provided by IDIBAPS (Barcelona), BTCIEN (Madrid), and BIOBANC-MUR (Murcia) Biobanks. Experimental procedures were approved by the Ethical Committee of Clinical Research at Ciudad Real University Hospital (SAF2016-75768-R).

\section{Histology}

Tissue was stored in $4 \%$ paraformaldehyde for 45 days and cryoprotected by immersion in $2 \%$ dimethyl sulfoxide (DMSO) and $10 \%$ glycerol for $48 \mathrm{~h}$, followed by $2 \%$ DMSO and $20 \%$ glycerol for a further $48 \mathrm{~h}$. Using a freezing sliding microtome, 10 series of $50-\mu \mathrm{m}$ sections were obtained. One 
TABLE 1 | Demographic and clinic-pathological features of the individuals used in this study.

\begin{tabular}{llcc}
\hline Diagnosis & Sex & Age & Brain weight (g) \\
\hline PD & M & 67 & 1425 \\
PD & M & 71 & 1275 \\
PD & F & 69 & 1065 \\
PD & $M$ & 55 & 790 \\
C & $M$ & 69 & 1451 \\
C & $M$ & 87 & 1000 \\
C & $M$ & 59 & 1400 \\
C & $M$ & 72 & 1600 \\
\hline
\end{tabular}

C, control; F, female; $M$, male; $P D$, Parkinson's disease.

A
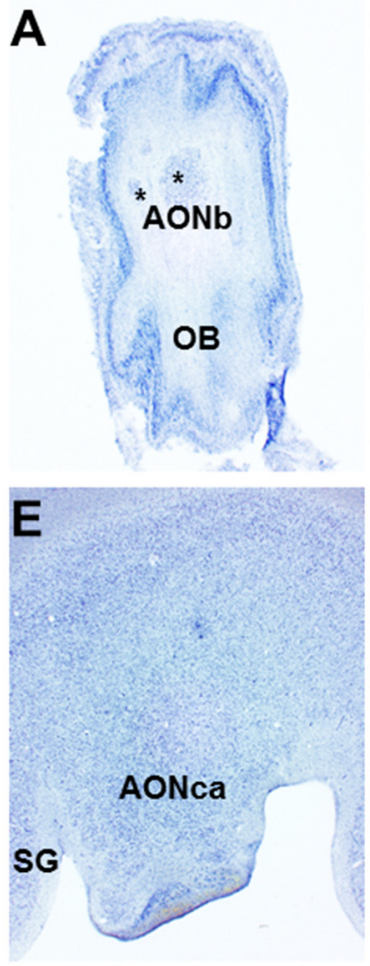

\section{B}
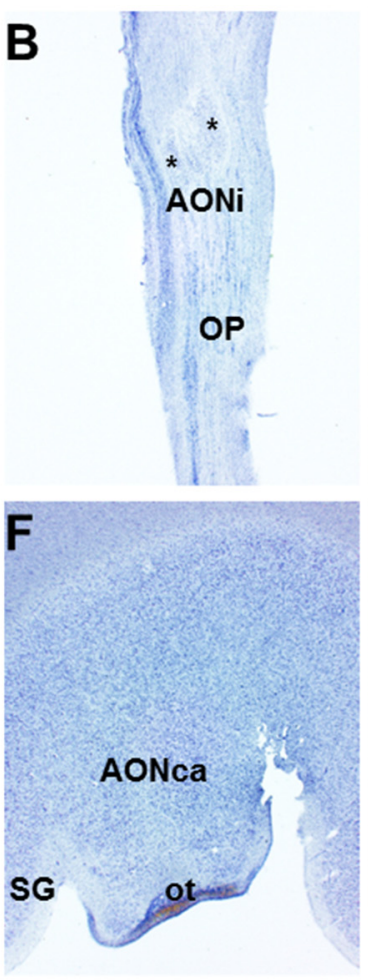
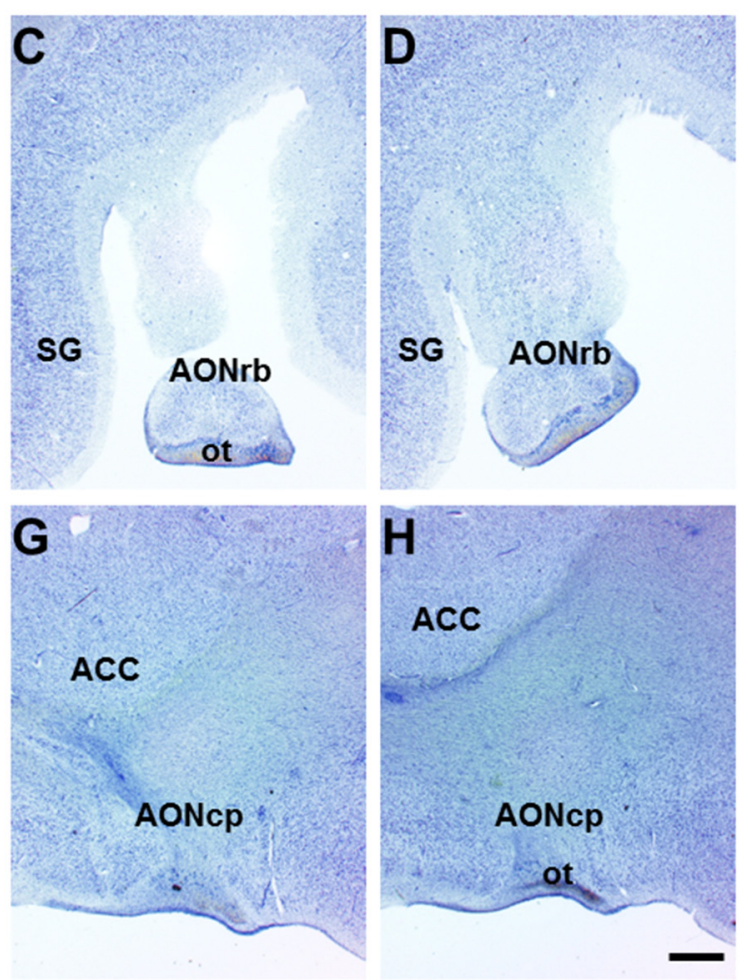

FIGURE 1 | Horizontal (olfactory bulb (OB) and olfactory peduncle (OP)) and coronal (frontal lobe) sections of the human brain. Nissl-stained horizontal sections of the human $\mathrm{OB}$ and $\mathrm{OP}$ show bulbar (A) and intrapeduncular (B) anterior olfactory nucleus (AON) showing diverse components (asterisks). In coronal sections of the frontal lobe, the retrobulbar (C,D), cortical anterior $\mathbf{( E , F ) ~ a n d ~ c o r t i c a l ~ p o s t e r i o r ~ ( G , H ) ~ A O N ~ a r e ~ d i s t i n g u i s h a b l e . ~ S c a l e ~ b a r , ~} 1300 \mu \mathrm{m}$. For abbreviations, see list.

of the series was Nissl-stained, while the second was used for immunohistochemistry against $\alpha$-synuclein; the third and fourth series were used for immunofluorescence analysis.

Two different immunofluorescent experiments were carried out. Sections were incubated with primary antibodies against $\alpha$-synuclein, parvalbumin and calretinin, or $\alpha$-synuclein, calbindin and somatostatin, followed by Alexa Fluorconjugated secondary antibodies (Table 2) according to previous protocols (Ubeda-Bañon et al., 2010; Flores-Cuadrado et al., 2017).

\section{TABLE 2 | Antibodies used in the present study.}

\begin{tabular}{|c|c|c|c|}
\hline Antigen & Dilution & Species & Secondary antibody (1/200) \\
\hline Calbindin D-28k. Swant (Marly, Switzerland) & $1: 1000$ & Rabbit polyclonal & Alexa Fluor ${ }^{\circledR} 488$ anti-rabbit. Molecular Probes (Eugene, OR, USA) \\
\hline Calretinin CR-769. Swant & $1: 1000$ & Rabbit polyclonal & Alexa Fluor ${ }^{\circledR} 488$ anti-rabbit. Molecular Probes \\
\hline Parvalbumin PVG-214. Swant & $1: 1000$ & Goat polyclonal & Alexa Fluor ${ }^{\circledR} 647$ anti-goat. Molecular Probes \\
\hline Somatostatin D-20. Santa Cruz (Dallas, TX, USA) & $1: 500$ & Goat polyclonal & Alexa Fluor ${ }^{\circledR} 647$ anti-goat. Molecular Probes \\
\hline$\alpha$-synuclein. Novocastra (Newcastle, UK) & $1: 20$ & Mouse monoclonal & Alexa Fluor ${ }^{\circledR} 555$ anti-mouse. Molecular Probes \\
\hline
\end{tabular}




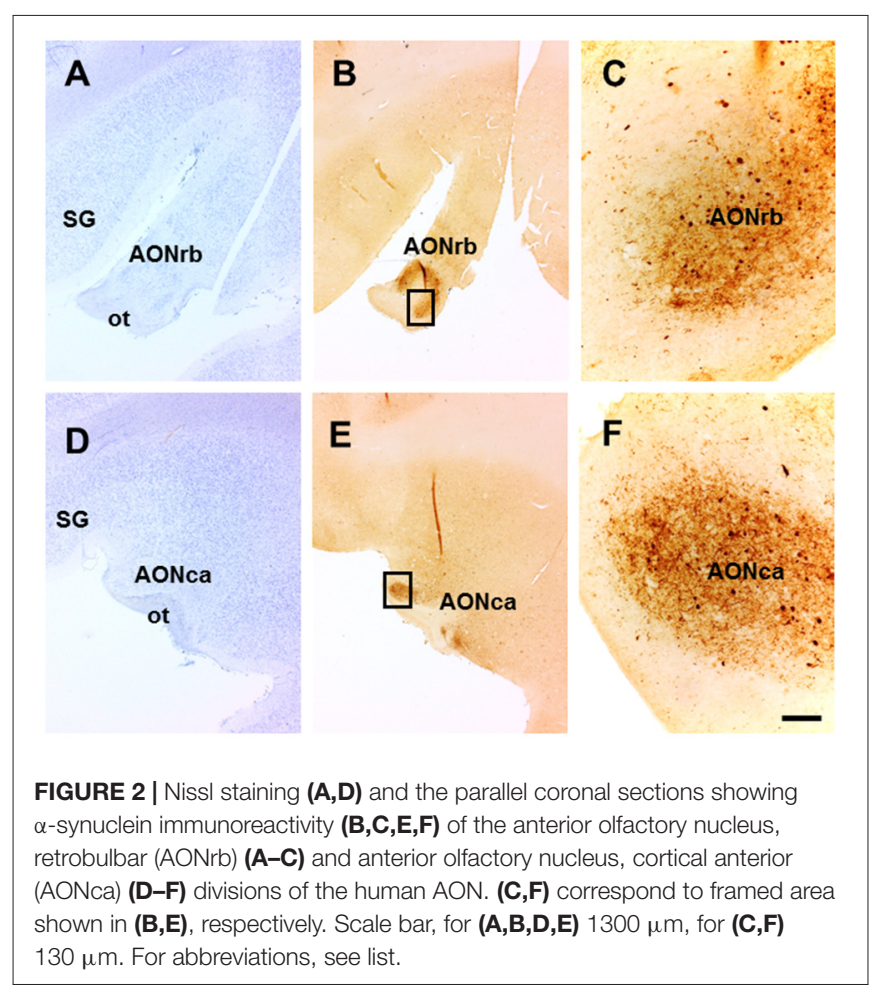

\section{Quantification}

Three divisions of the AON-the AONrb, and the AONca and AONcp divisions (Figure 1) - which were identified in parallel Nissl-stained sections at approximately $12.5,10.0$ and $7.5 \mathrm{~mm}$ from Bregma (Mai et al., 2008), were analyzed in each case $(n=8$; Figure 2).

Using LSM 800 confocal microscope (Zeiss, Jena, Germany) a total of 192 images at $20 \times$ magnifications were acquired: four random images in each division $(n=3)$ of each case $(n=8)$ of each immunofluorescent staining combination $(n=2)$. In every image, four independent channels were acquired according to the three secondary antibodies used (Table 2), including DAPI.

For analysis, ZEN (Zeiss, black edition 10.0) and ImageJ software (National Institutes of Health, Bethesda, MD, USA, $1.47 \mathrm{v}$ ) were used. In order to estimate changes in the expression of markers in neuronal cell bodies alone, changes in expression of markers in neuronal cell bodies and neurites, and in co-localization of markers with $\alpha$-synucein, three kinds of parameters were measured: cells $/ \mathrm{mm}^{2}, \%$ of area fraction and $\%$ of co-localization, respectively.

For estimating the number of positive cell bodies (cells $/ \mathrm{mm}^{2}$ ) of calcium binding proteins and somatostatin, the images were analyzed with ImageJ using a protocol for the automated counting of stained cells as previously reported (Flores-Cuadrado et al., 2015). The corresponding channel of the marker analyzed was selected in every image and the images were converted to a binary 8-bit grayscale and a histogram was generated. The mode was multiplied by $0.6(60 \%)$ to obtain the threshold for distinguishing specific cell labeling from background. The thresholds were: 71 for somatostatin-positive cells, 30 for calbindin-positive cells, 40 for calretinin-positive cells and 90 for parvalbumin-positive cells.

In order to quantify the total expression of markers, including cell bodies and neurites, \% of area fraction was analyzed as previously described (Saiz-Sanchez et al., 2012). Using the the same images as above, the labeled area was compared to un-labeled tissue as an automatic parameter of ImageJ.

For co-localization of different neural and pathological markers, ZEN and ImageJ software was used. Using two channels from every $2 \mathrm{D}$ image, the total number of cells expressing a neural marker was compared to the number of cells that also co-expressed $\alpha$-synuclein. In this way, co-localization as a percentage of total cells was obtained.

Data were analyzed using GraphPad Prism software (GraphPad Inc., San Diego, CA, USA, v.6). The normality of the samples $(P>0.05)$ was evaluated with the Kolmogorov-Smirnov test and group means were compared with the Mann-Whitney $U$ test (non-parametric data). Data are expressed as mean \pm standard error of the mean to estimate the reliability of the mean. Differences were considered statistically significant at $P<0.05$.

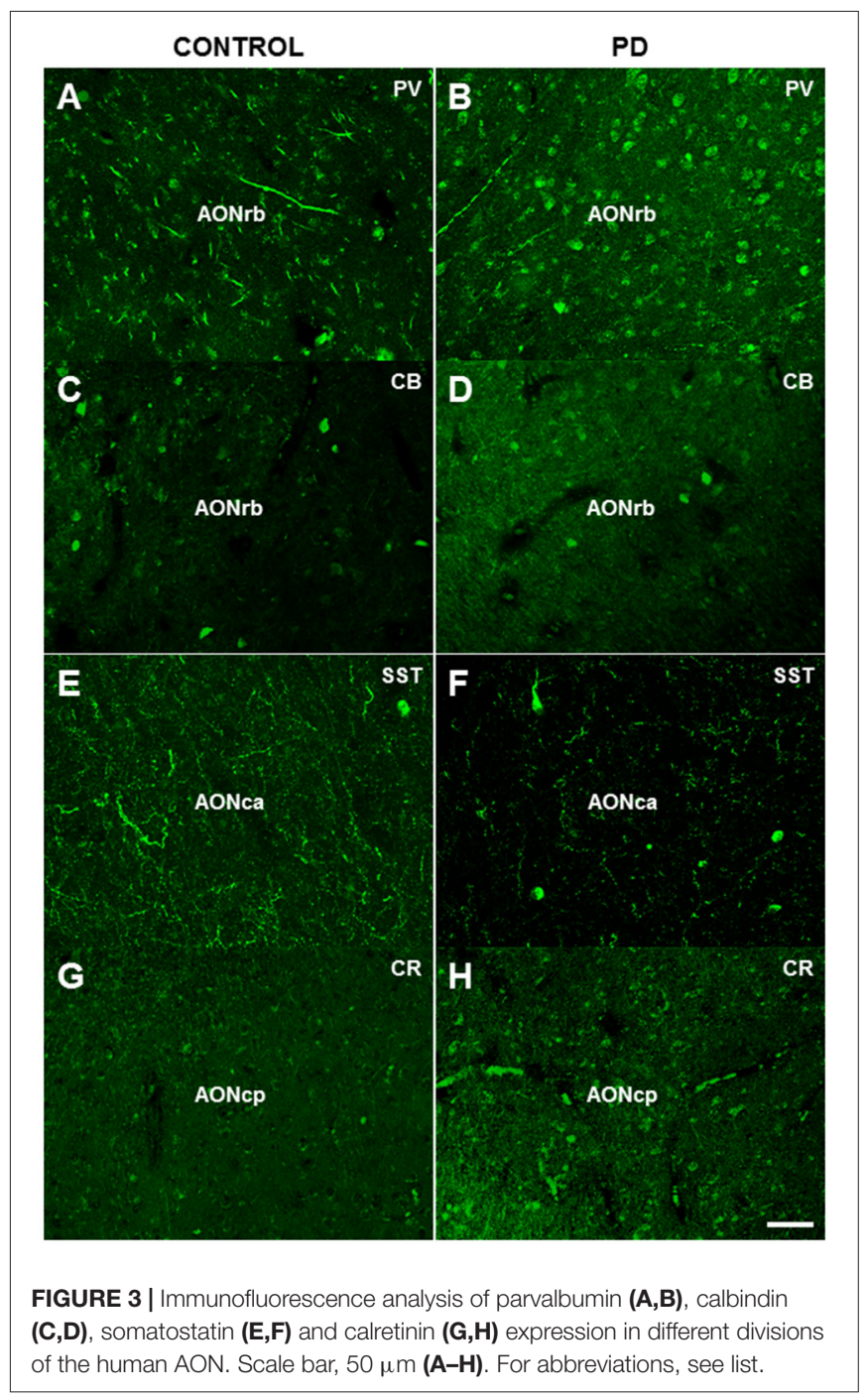




\section{A AONrb}

AONca

AONcp

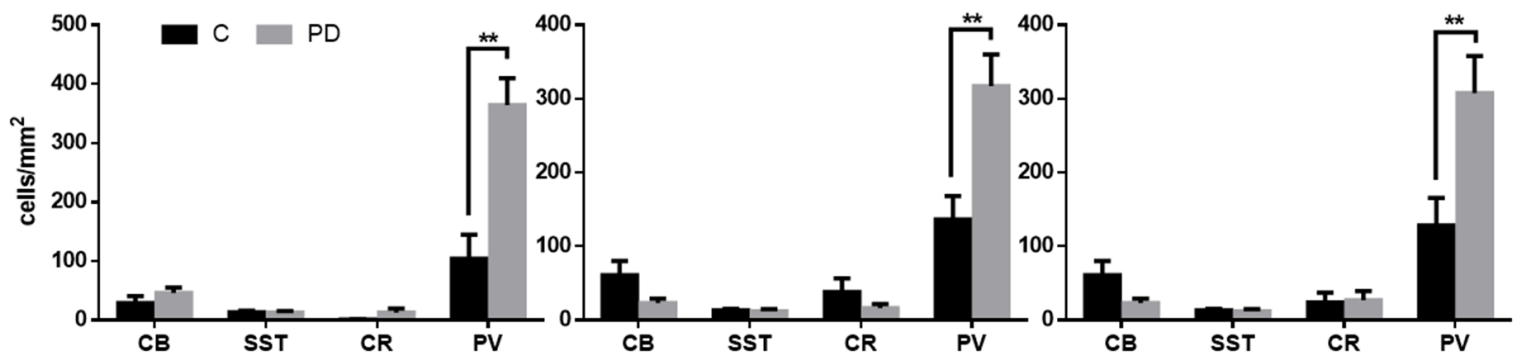

B

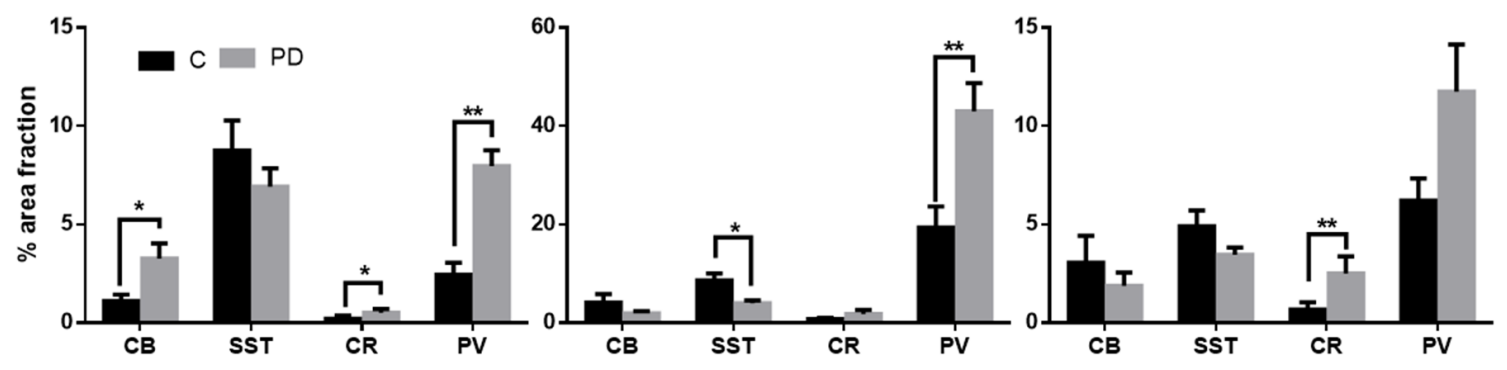

FIGURE 4 | Graphs show cells/mm² (A) and \% of area fraction (B) expression of calbindin, somatostatin, calretinin and parvalbumin in the different portions of the AON in Parkinson's disease (PD) and control (C) cases. ${ }^{*} p<0.05,{ }^{* *} p<0.01$.

\section{RESULTS}

The human AON is a complex and multiple-portion structure that is poorly characterized. Classical descriptions include several subdivisions along the olfactory system (Crosby and Humprey, 1941) that have been renamed as the bulbar, intrapeduncular, retrobulbar, cortical anterior and cortical posterior divisions (Ubeda-Bañon et al., 2010). Horizontal sections of the human $\mathrm{OB}$ (Figure 1A) and olfactory peduncle (OP; Figure 1B) showed several components of the anterior olfactory nucleus, bulbar (AONb; Figure 1A, asterisks) and anterior olfactory nucleus, intrapeduncular (AONi) AON (Figure 1B, asterisks). In coronal sections, the AONrb displayed a typical horseshoe form (Figures 1C,D) that once incorporated to the basal prosencephalon, merged into the AONca (Figures 1E,F), and caudally, into the AONcp (Figures 1G,H).

Using sequential Nissl-stained sections, the AONrb (Figure 2A), AONca (Figure 2D), and AONcp (not shown) were analyzed. Immunohistochemical analysis of $\alpha$-synuclein expression revealed specific immunoreactivity in different AON divisions includig the AONrb (Figure 2B), AONca (Figure 2E) and AONcp (not shown). High-power images demonstrated the preferential labeling of Lewy bodies and neurites in the AONrb and AONca divisions, respectively (Figures $2 \mathrm{C}, \mathbf{F}$ ).

Fluorescent labeling (Figures 3, 5) was analyzed using three parameters: (1) we compared the respective neuronal markers in the neuronal cell bodies $\left(\right.$ cell $/ \mathrm{mm}^{2}$ ) located in the divisions of the AON of PD and control cases (Figure 4B); (2) we compared the expression of these markers in the neuronal cell bodies and neurites (\% of area fraction) in the divisions of the
AON of PD and control cases (Figure 4A); (3) we analyzed the co-localization of these neuronal markers with $\alpha$-synuclein (Figure 5).

Immunofluorescent analyses revealed significantly higher expression of parvalbumin in the neuronal cell bodies $\left(\mathrm{cell} / \mathrm{mm}^{2}\right)$ in all of the AON divisions of $\mathrm{PD}$ cases compared with controls: the AONrb $(P=0.001$; Figures 3A,B, 4A), AONca $(P=0.001$; Figure 4A) and the AONpc $(P=0.087$; Figure 4A). No significant differences were found in the expression of calbindin, somatostatin, or calretinin in the above regions between the two goups (Figures 3C-H, 4A).

There was significanlty higher expression of calbindin $(P=0.0178$; Figures 3C,D, 4B), calretinin $(P=0.0366$; Figure 4B) and parvalbumin $(P=0.0001$; Figures $3 \mathbf{A}, \mathbf{B}, \mathbf{4 B})$ in the cell bodies and neurites (\% of area fraction) of neurons in the AONrb of PD patients compared with controls. There was also significantly higher expression of parvalbumin in the neurites (Figure 4B) of neurons in the AONca of PD cases compared with controls $(P=0.0031$; Figure 4B). In contrast, somatostatin expression was significantly downregulated in the AONac of PD cases $(P=0.0113$; Figures 3E,F, 4B). Finally, calretinin expression was significantly higher in the cell bodies plus neurites of neurons in the AONpc of PD patients $(P=0.0096$; Figures 3G,H, 4B).

Co-localization of $\alpha$-synuclein and the above neural markers in $\mathrm{PD}$ cases was analyzed to investigate involvement of $\alpha$-synucleinopathy among different neuronal subtypes, and is summarized in Figure 5. Examples of co-localization of $\alpha$-synuclein in the AONrb (Figures 5A,B), the AONca (Figures 5C,D), and the AONpc (Figures 5E,F) with calretenin, calbindin, parvalbumin and somatistatin are shown. Analyses of 


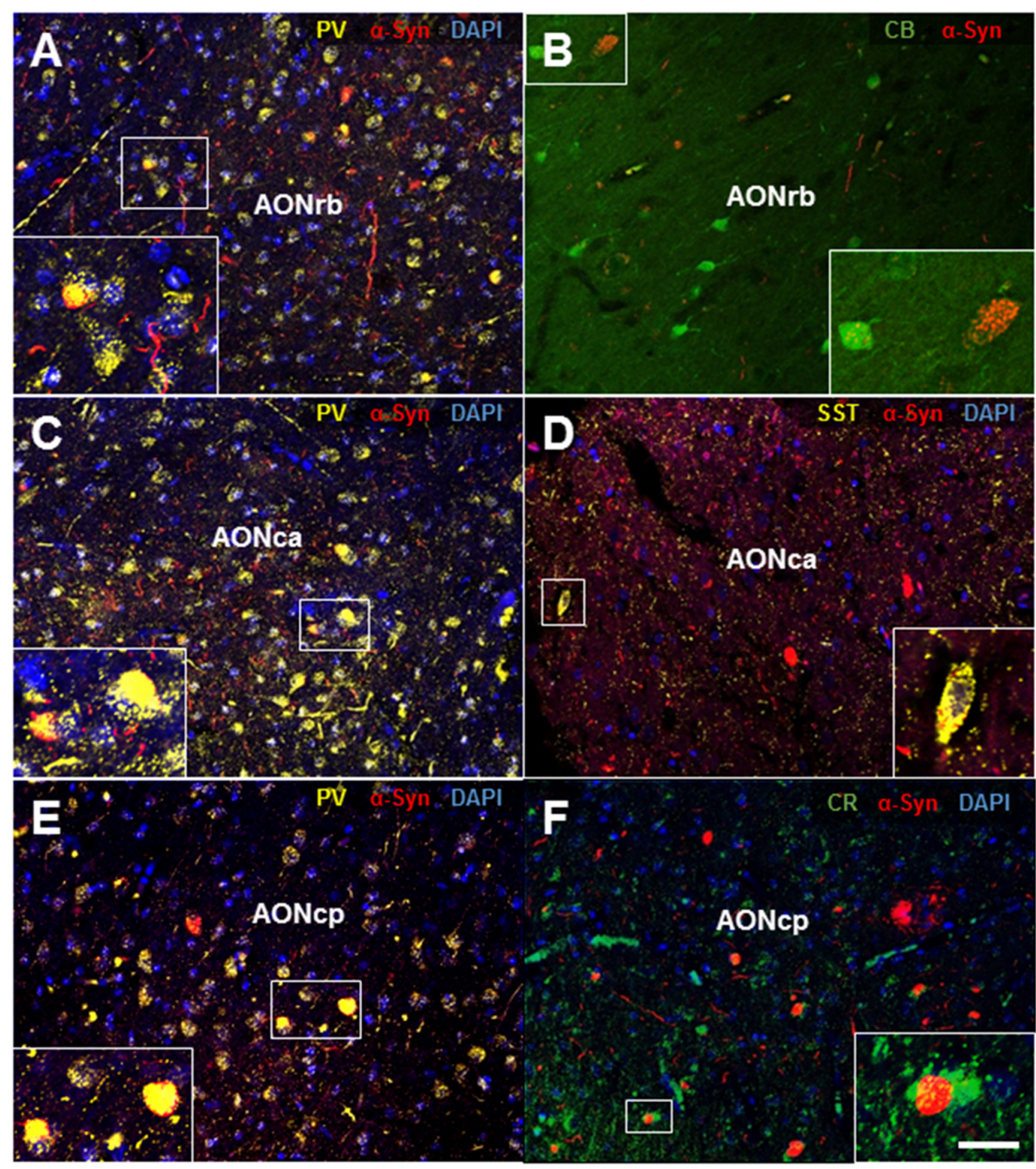

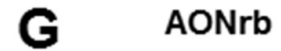

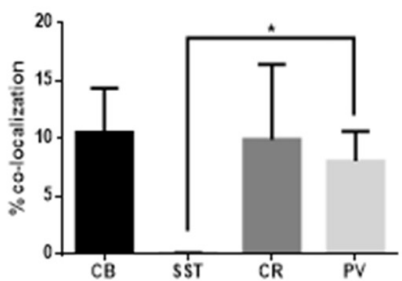

AONca

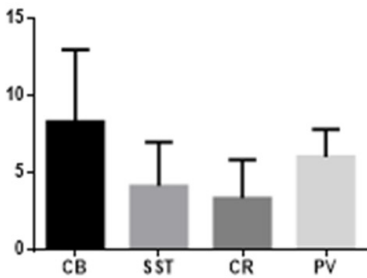

AONcp

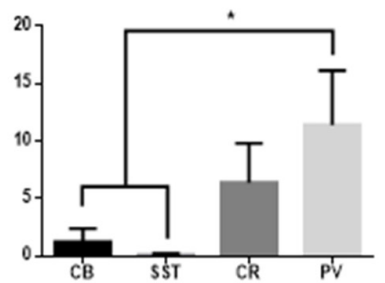

FIGURE 5 | Immunofluorescence analysis of parvalbumin (A,C,E), calbindin (B), somatostatin (E) and calretinin (F) expression and their co-localization with $\alpha$-synuclein in different divisions of the human AON. Percent is referred to total number of cells counted that express a neural marker and the fraction of which co-express $\alpha$-synuclein. Percent of co-localization of $\alpha$-synuclein with the interneuron markers indicated (G) in the AONrb, AONca and anterior olfactory nucleus, cortical posterior (AONcp) divisions of the AON. Scale bar, $50 \mu \mathrm{m}$ (A-F); $21.25 \mu \mathrm{m}$ in frame (A), $24.53 \mu \mathrm{m}$ in frame (B), $16.72 \mu \mathrm{m}$ in frame (C), $10.31 \mu \mathrm{m}$ in frame (D), $16.43 \mu \mathrm{m}$ in frame (E), $12.5 \mu \mathrm{m}$ in frame (F). For abbreviations, see list. ${ }^{*} p<0.05$.

the percentage of cells where co-localization occurred revealed that neurons expressing the calcium-binding proteins (calretinin, calbindin and parvalbumin) had the highest percentages of $\alpha$-synuclein co-localization. Somatostatin $/ \alpha$-synuclein-positive cells were rare, although there were higher percentages in the AONca (Figures 5D,G).

Significant differences were also observed between somatostatin and parvalbumin expression in the AONrb 
of $\mathrm{PD}$ cases $(P=0.0113$; Figure 5G $)$ and between somatostatin and parvalbumin expression and calbindin and paravalbumin expression in the AONcp $(P=0.0124$; Figure 5G).

\section{DISCUSSION}

We found that increased expression of calcium-binding proteins (calretinin, calbindin and parvalbumin), particularly parvalbumin, correlated with $\alpha$-synuclein co-localization in the different divisions of the AON. In contrast, the decreased neuritic expression of somatostatin in the AONca also led to decreased $\alpha$-synuclein co-localization. Varied calbindin expression (\% of area fraction) and calbindin/ $\alpha$-synuclein co-localization among the divisions of the AON were also found. Regarding calretinin expression, we did not observe differences in any of the AON divisions in cells $/ \mathrm{mm}^{2}$, but we did find significant increases in the $\%$ of area fraction in both the AONrb and AONcp. This contrast to recent data reporting significant reductions in the number of calretininpositive periglomerular and granular cells in the $\mathrm{OB}$ of $\mathrm{PD}$ cases compared to controls (Cave et al., 2016). Data from this experiment support the idea for differential regional $\alpha$-synuclein involvement; and therefore, we believe the divisions of the AON to be diverse and thus need to be independently analyzed.

There are several limitations to this study. First and foremost, the interpretation of the data obtained in this study is limited by the number of cases available. Future studies including larger number of cases are needed.

This report is the first study comparing both the expression of markers of different neuronal populations in the AONrb, AONca, and AONcp of PD cases and controls as well as $\alpha$-synuclein distribution in these respective areas. Previous reports on $\alpha$-synuclein distribution in the OB focused on the AONb and/or AONi (Del Tredici et al., 2002; Braak et al., 2003a,b; Attems et al., 2014; Del Tredici and Braak, 2016; Braak and Del Tredici, 2017) and for the most part, did not include co-localization with neural markers (Sengoku et al., 2008).

In this context, it is especially interesting to investigate the differential vulnerability of interneuron populations in the AON since this structure is implicated in hyposmia (Hawkes and Shephard, 1993; Jellinger, 2009) and shows early and preferential involvement in $\alpha$-synucleinopathy (Sengoku et al., 2008; UbedaBañon et al., 2010; Attems et al., 2014); suggesting that it is an important structure in PD etiology (Ubeda-Bañon et al., 2014). The early and preferential involvement of the AON in PD could be due to the multiple interconnections of this structure with various other regions of the brain as shown in rodents (Brunjes et al., 2005). Indeed, a direct projection from the substantia nigra to the OB has recently been described (Höglinger et al., 2015). Therefore, as the AON in the human brain is composed of at least five different divisions (Ubeda-Bañon et al., 2014; Figure 1), each of these needs to be further characterized in order to establish accurate analysis.

Overall, our results show high levels of calcium-binding proteins - specfically of parvalbumin-in the AON and reduced neuritic somatostatin expression in the AONca; in contrast to what is observed in the substantia nigra (Hardman et al., 1996).

In the human amygdala, we reported decreased expression of somatostatin in PD cases (Flores-Cuadrado et al., 2017), but, in contrast to the current data, we also found decreased expression of parvalbumin (Flores-Cuadrado et al., 2017). This difference could be due to the fact that the number of parvalbumin-positive cells $/ \mathrm{mm}^{2}$ is 10 times higher in the AON (Figure 4) as compared to the human amygdala (Flores-Cuadrado et al., 2017). Also, the intrinsic dendrites vs. somatostatin-positive axons from distal sites cannot be discarded (Lepousez et al., 2010). Interestingly, calcium-binding proteins, but rarely somatostatin, co-localized with $\alpha$-synuclein, which was in agreement with previous studies (Flores-Cuadrado et al., 2016, 2017).

In Alzheimer's disease, somatostatin expression is decreased by $50 \%$ in the AONca and co-localizes with amyloid $\beta$ (SaizSanchez et al., 2010), whereas parvalbumin and somatostatin levels are up- and downregulated, respectively, in the piriform cortex (Saiz-Sanchez et al., 2015, 2016). Common patterns of differential vulnerability among different interneuron populations due to distinct proteinopathies (Epelbaum et al., 2009) deserves additional analysis in structures like the AON, which is involved early and preferentially.

Our results suggest a potential differential vulnerability that may be due to $\alpha$-synucleinopathy among interneurons populations in different divisions of the human AON. It is unclear to what extent cells expressing calcium-binding proteins can buffer the pathological effects of $\alpha$-synuclein and somatostatin-positive neurons are induced to change their cell body size and/or dendritic expression by non-aggregated $\alpha$-synuclein isoforms; these are questions that will be addressed in future studies.

\section{AUTHOR CONTRIBUTIONS}

IU-B, AF-C, DS-S and AM-M: study design, discussion and writing. IU-B, AF-C and DS-S: tissue section. IU-B and AF-C: immunohistochemistry and data analysis. IU-B and DS-S: image capture. IU-B, AF-C, DS-S and AM-M: discussion and writing.

\section{FUNDING}

This study was sponsored by the Spanish Ministry of Economy and Competitiveness-FEDER (grant \# SAF2016-75768-R) to AM-M.

\section{ACKNOWLEDGMENTS}

We are indebted to the IDIBAPS, BTCIEN and BIOBANC-MUR Biobanks for sample and data procurement. We thank International Science Editing for the English edition of this manuscript. 


\section{REFERENCES}

Attems, J., Walker, L., and Jellinger, K. A. (2014). Olfactory bulb involvement in neurodegenerative diseases. Acta Neuropathol. 127, 459-475. doi: 10.1007/s00401-014-1261-7

Berg, D., Postuma, R. B., Adler, C. H., Bloem, B. R., Chan, P., Dubois, B., et al. (2015). MDS research criteria for prodromal Parkinson's disease. Mov. Disord. 30, 1600-1611. doi: 10.1002/mds.26431

Braak, H., and Del Tredici, K. (2017). Neuropathological staging of brain pathology in sporadic Parkinson's disease: separating the wheat from the chaff. J. Parkinsons Dis. 7, S73-S87. doi: 10.3233/jpd-179001

Braak, H., Del Tredici, K., Rüb, U., de Vos, R. A., Jansen Steur, E. N., and Braak, E. (2003a). Staging of brain pathology related to sporadic Parkinson's disease. Neurobiol. Aging 24, 197-211. doi: 10.1016/S0197-4580(02)00065-9

Braak, H., Rüb, U., Gai, W. P., and Del Tredici, K. (2003b). Idiopathic Parkinson's disease: possible routes by which vulnerable neuronal types may be subject to neuroinvasion by an unknown pathogen. J. Neural Transm. 110, 517-536. doi: 10.1007/s00702-002-0808-2

Brunjes, P. C., Illig, K. R., and Meyer, E. A. (2005). A field guide to the anterior olfactory nucleus (cortex). Brain Res. Rev. 50, 305-335. doi: 10.1016/j. brainresrev.2005.08.005

Burke, R. E., Dauer, W. T., and Vonsattel, J. P. (2008). A critical evaluation of the Braak staging scheme for Parkinson's disease. Ann. Neurol. 64, 485-491. doi: 10.1002/ana.21541

Cave, J. W., Fujiwara, N., Weibman, A. R., and Baker, H. (2016). Cytoarchitectural changes in the olfactory bulb of Parkinson's disease patients. NPJ Parkinsons Dis. 2:16011. doi: 10.1038/npjparkd.2016.11

Crosby, E. C., and Humprey, T. (1941). Studies of the vertebrate telencephalon. II. The nuclear pattern of the anterior olfactory nucleus, tuberculum olfactorium and the amygdaloid complex in adult man. J. Comp. Neurol. 74, 309-352. doi: $10.1002 / \mathrm{cne} .900740209$

Del Tredici, K., and Braak, H. (2016). Review: sporadic Parkinson's disease: development and distribution of $\alpha$-synuclein pathology. Neuropathol. Appl. Neurobiol. 42, 33-50. doi: 10.1111/nan.12298

Del Tredici, K., Rüb, U., De Vos, R. A., Bohl, J. R., and Braak, H. (2002). Where does parkinson disease pathology begin in the brain? J. Neuropathol. Exp. Neurol. 61, 413-426. doi: 10.1093/jnen/61.5.413

Doty, R. L. (2012a). Olfactory dysfunction in Parkinson disease. Nat. Rev. Neurol. 8, 329-339. doi: 10.1038/nrneurol.2012.80

Doty, R. L. (2012b). Olfaction in Parkinson's disease and related disorders. Neurobiol. Dis. 46, 527-552. doi: 10.1016/j.nbd.2011.10.026

Doty, R. L. (2017). Olfactory dysfunction in neurodegenerative diseases: is there a common pathological substrate? Lancet Neurol. 16, 478-488. doi: 10.1016/S1474-4422(17)30123-0

Epelbaum, J., Guillou, J. L., Gastambide, F., Hoyer, D., Duron, E., and Viollet, C. (2009). Somatostatin, Alzheimer's disease and cognition: an old story coming of age? Prog. Neurobiol. 89, 153-161. doi: 10.1016/j.pneurobio.2009. 07.002

Flores-Cuadrado, A., Ubeda-Bañon, I., Saiz-Sanchez, D., de la Rosa-Prieto, C., and Martinez-Marcos, A. (2015). $\alpha$-synuclein staging in the amygdala of a Parkinson's disease model: cell types involved. Eur. J. Neurosci. 41, 137-146. doi: $10.1111 /$ ejn. 12763

Flores-Cuadrado, A., Ubeda-Baoon, I., Saiz-Sanchez, D., de la Rosa-Prieto, C., and Martinez-Marcos, A. (2016). Hippocampal $\alpha$-synuclein and interneurons in Parkinson's disease: data from human and mouse models. Mov. Disord. 31, 979-988. doi: 10.1002/mds.26586

Flores-Cuadrado, A., Ubeda-Bañon, I., Saiz-Sanchez, D., and MartinezMarcos, A. (2017). $\alpha$-synucleinopathy in the human amygdala in Parkinson disease: differential vulnerability of somatostatin- and parvalbumin-expressing neurons. J. Neuropathol. Exp. Neurol. 76, 754-758. doi: 10.1093/jnen/ $\mathrm{nlx} 054$

Goedert, M., Spillantini, M. G., Del Tredici, K., and Braak, H. (2013). 100 years of Lewy pathology. Nat. Rev. Neurol. 9, 13-24. doi: 10.1038/nrneurol.2012.242

Hardman, C. D., McRitchie, D. A., Halliday, G. M., Cartwright, H. R., and Morris, J. G. (1996). Substantia nigra pars reticulata neurons in Parkinson's disease. Neurodegeneration 5, 49-55. doi: 10.1006/neur.1996.0007

Hawkes, C. H., and Shephard, B. C. (1993). Selective anosmia in Parkinson's disease? Lancet 341, 435-436. doi: 10.1016/0140-6736(93)93027-x
Höglinger, G. U., Alvarez-Fischer, D., Arias-Carrion, O., Djufri, M., Windolph, A., Keber, U., et al. (2015). A new dopaminergic nigro-olfactory projection. Acta Neuropathol. 130, 333-348. doi: 10.1007/s00401-015-1451-y

Jellinger, K. A. (2009). Olfactory bulb $\alpha$-synucleinopathy has high specificity and sensitivity for Lewy body disorders. Acta Neuropathol. 117, 215-216; author reply 217-218. doi: 10.1007/s00401-008-0454-3

Jucker, M., and Walker, L. C. (2013). Self-propagation of pathogenic protein aggregates in neurodegenerative diseases. Nature 501, 45-51. doi: $10.1038 /$ nature 12481

Kalia, L. V., and Kalia, S. K. (2015). $\alpha$-synuclein and Lewy pathology in Parkinson's disease. Curr. Opin. Neurol. 28, 375-381. doi: 10.1097/WCO. 0000000000000215

Kalia, L. V., and Lang, A. E. (2015). Parkinson's disease. Lancet 386, 896-912. doi: 10.1016/S0140-6736(14)61393-3

Klingelhoefer, L., and Reichmann, H. (2015). Pathogenesis of Parkinson disease-the gut-brain axis and environmental factors. Nat. Rev. Neurol. 11, 625-636. doi: 10.1038/nrneurol.2015.197

Lees, A. J., Hardy, J., and Revesz, T. (2009). Parkinson's disease. Lancet 373, 2055-2066. doi: 10.1016/S0140-6736(09)60492-X

Lepousez, G., Csaba, Z., Bernard, V., Loudes, C., Videau, C., Lacombe, J., et al. (2010). Somatostatin interneurons delineate the inner part of the external plexiform layer in the mouse main olfactory bulb. J. Comp. Neurol. 518, 1976-1994. doi: 10.1002/cne.22317

Mai, J. K., Paxinos, G., and Voss, T. (2008). Atlas of the Human Brain. New York, NY: Elsevier.

Pearce, R. K., Hawkes, C. H., and Daniel, S. E. (1995). The anterior olfactory nucleus in Parkinson's disease. Mov. Disord. 10, 283-287. doi: 10.1002/mds. 870100309

Poewe, W., Seppi, K., Tanner, C. M., Halliday, G. M., Brundin, P., Volkmann, J., et al. (2017). Parkinson disease. Nat. Rev. Dis. Primers 3:17013. doi: $10.1038 /$ nrdp. 2017.13

Postuma, R. B., and Berg, D. (2016). Advances in markers of prodromal Parkinson disease. Nat. Rev. Neurol. 12, 622-634. doi: 10.1038/nrneurol.2016.152

Postuma, R. B., Berg, D., Stern, M., Poewe, W., Olanow, C. W., Oertel, W., et al. (2015). MDS clinical diagnostic criteria for Parkinson's disease. Mov. Disord. 30, 1591-1601. doi: 10.1002/mds.26424

Saito, Y., Shioya, A., Sano, T., Sumikura, H., Murata, M., and Murayama, S. (2016). Lewy body pathology involves the olfactory cells in Parkinson's disease and related disorders. Mov. Disord. 31, 135-138. doi: 10.1002/mds.26463

Saiz-Sanchez, D., De la Rosa-Prieto, C., Ubeda-Banon, I., and Martinez-Marcos, A. (2015). Interneurons, tau and amyloid- $\beta$ in the piriform cortex in Alzheimer's disease. Brain Struct. Funct. 220, 2011-2025. doi: 10.1007/s00429-014-0771-3

Saiz-Sanchez, D., Flores-Cuadrado, A., Ubeda-Bañon, I., de la Rosa-Prieto, C., and Martinez-Marcos, A. (2016). Interneurons in the human olfactory system in Alzheimer's disease. Exp. Neurol. 276, 13-21. doi: 10.1016/j.expneurol.2015. 11.009

Saiz-Sanchez, D., Ubeda-Bañon, I., De la Rosa-Prieto, C., and Martinez-Marcos, A. (2012). Differential expression of interneuron populations and correlation with amyloid- $\beta$ deposition in the olfactory cortex of an A $\beta P P / P S 1$ transgenic mouse model of Alzheimer's disease. J. Alzheimers Dis. 31, 113-129. doi: 10.3233/JAD2012-111889

Saiz-Sanchez, D., Ubeda-Bañon, I., de la Rosa-Prieto, C., Argandoña-Palacios, L., Garcia-Munozguren, S., Insausti, R., et al. (2010). Somatostatin, tau, and $\beta$-amyloid within the anterior olfactory nucleus in Alzheimer disease. Exp. Neurol. 223, 347-350. doi: 10.1016/j.expneurol.2009.06.010

Salat, D., Noyce, A. J., Schrag, A., and Tolosa, E. (2016). Challenges of modifying disease progression in prediagnostic Parkinson's disease. Lancet Neurol. 15, 637-648. doi: 10.1016/s1474-4422(16)00060-0

Sauerbier, A., Qamar, M. A., Rajah, T., and Chaudhuri, K. R. (2016). New concepts in the pathogenesis and presentation of Parkinson's disease. Clin. Med. 16, 365-370. doi: 10.7861/clinmedicine.16-4-365

Schapira, A. H. V., Chaudhuri, K. R., and Jenner, P. (2017). Non-motor features of Parkinson disease. Nat. Rev. Neurosci. 18:509. doi: 10.1038/nrn. 2017.91

Sengoku, R., Saito, Y., Ikemura, M., Hatsuta, H., Sakiyama, Y., Kanemaru, K., et al. (2008). Incidence and extent of Lewy body-related $\alpha$-synucleinopathy in aging human olfactory bulb. J. Neuropathol. Exp. Neurol. 67, 1072-1083. doi: 10.1097/NEN.0b013e31818b4126 
Spillantini, M. G., Schmidt, M. L., Lee, V. M., Trojanowski, J. Q., Jakes, R., and Goedert, M. (1997). $\alpha$-synuclein in Lewy bodies. Nature 388, 839-840. doi: $10.1038 / 42166$

Stiasny-Kolster, K., Doerr, Y., Möller, J. C., Höffken, H., Behr, T. M., Oertel, W. H., et al. (2005). Combination of 'idiopathic' REM sleep behaviour disorder and olfactory dysfunction as possible indicator for $\alpha$-synucleinopathy demonstrated by dopamine transporter FP-CIT-SPECT. Brain 128, 126-137. doi: 10.1093/brain/awh322

Tolosa, E., and Pont-Sunyer, C. (2011). Progress in defining the premotor phase of Parkinson's disease. J. Neurol. Sci. 310, 4-8. doi: 10.1016/j.jns.2011.05.027

Ubeda-Bañon, I., Saiz-Sanchez, D., de la Rosa-Prieto, C., Argandoña-Palacios, L., Garcia-Muñozguren, S., and Martinez-Marcos, A. (2010). $\alpha$-synucleinopathy in the human olfactory system in Parkinson's disease: involvement of calciumbinding protein- and substance P-positive cells. Acta Neuropathol. 119, 723-735. doi: 10.1007/s00401-010-0687-9

Ubeda-Bañon, I., Saiz-Sanchez, D., de la Rosa-Prieto, C., and Martinez-Marcos, A. (2014). $\alpha$-synuclein in the olfactory system in Parkinson's disease: role of neural connections on spreading pathology. Brain Struct. Funct. 219, 1513-1526. doi: 10.1007/s00429-013-0651-2

Walker, L. C., and Jucker, M. (2015). Neurodegenerative diseases: expanding the prion concept. Annu. Rev. Neurosci. 38, 87-103. doi: 10.1146/annurev-neuro071714-033828

Conflict of Interest Statement: The authors declare that the research was conducted in the absence of any commercial or financial relationships that could be construed as a potential conflict of interest.

Copyright (c) 2017 Ubeda-Bañon, Flores-Cuadrado, Saiz-Sanchez and MartinezMarcos. This is an open-access article distributed under the terms of the Creative Commons Attribution License (CC BY). The use, distribution or reproduction in other forums is permitted, provided the original author(s) or licensor are credited and that the original publication in this journal is cited, in accordance with accepted academic practice. No use, distribution or reproduction is permitted which does not comply with these terms. 